\title{
SOCIEDADE E NATUREZA: INTERPRETAÇÕES, REFLEXOS NA EDUCAÇÃO AMBIENTAL NO BRASIL E A NECESSIDADE DO DEVIR
}

\author{
Thayanna Maria Medeiros Santos ${ }^{1}$ \\ Bartolomeu Israel de Souza²
}

Resumo: Considerando a necessidade de trazer novos elementos para resolução da problemática que envolve a Educação Ambiental, no aspecto referente a sua abordagem dentro dos espaços educativos, havendo a necessidade de uma inserção mais crítica e reflexiva, através de um ensaio bibliográfico crítico, esse artigo efetua reflexão das relações entre a Sociedade e Natureza a partir das correntes ambientais Antropocentrismo e Biocentrismo, destacando algumas das suas consequências para a Educação Ambiental no Brasil. Foi analisado o Antropoceno, não enquanto conceito e perspectiva de uma nova era geológica, mas enquanto oportunidade educacional para reformular e questionar as relações e fronteiras entre Sociedade-Natureza. Compreendendo este conceito como abordagem mais atual e condizente com a realidade, cuja perspectiva é transformação social, científica e tecnológica, possibilitando as sociedades tomarem consciência que integram uma "nova" Natureza, uma construção sustentável e duradoura das relações Homem-Natureza, deixando de lado o arcaísmo que compreende a Natureza intocada, com o modernismo cego da ciência cartesiana.

Palavras-chave: Meio Ambiente; Sociedade; Abordagens Filosóficas.

Abstract: Necessary the need to bring new elements to solve the problem involving Environmental Education, no aspect referring to its approach within educational spaces, with the need for a more critical and reflective insertion, through a critical bibliographic essay, this article reflects of the relationships between Society and Nature from the environmental currents Anthropocentrism and Biocentrism, highlighting some of their consequences for Environmental Education in Brazil. The Anthropocene was analyzed, not as a concept and perspective of a new geological age, but as an educational opportunity to reformulate and question the relations and boundaries between Society-Nature. Understanding this concept as a more current approach and consistent with reality, whose perspective is social, scientific and technological transformation, enabling societies to become aware that they integrate a "new" Nature, a sustainable and lasting construction of Man-Nature relations, leaving aside the archaism that understands Nature untouched, with the blind modernism of Cartesian science.

Key words: Environment; Society; Philosophical Approaches.

1 Universidade Federal da Paraíba. E-mail: thayannamdrs@hotmail.com
2 Universidade Federal da Paraíba. E-mail: $\underline{\text { bartolomeuisrael@gmail.com }}$ 


\section{Introdução}

O desenraizamento do Homem com o mundo natural, a afirmação mental e material cada vez mais firme ao longo dos anos foi gerando uma ruptura e desconexão deste mesmo Homem com o ambiente, causando uma série de problemas como por exemplo os relacionados as questões ambientais.

Este desenraizamento é notório e presente no modo como a ciência é produzida, tendo origem, na maioria dos casos, a partir da fragmentação, do isolamento e da descontextualização das situações para com a realidade onde estão inseridas.

Do mesmo modo ocorre nos processos educativos ambientais no ensino formal e, no caso do Brasil, o conteúdo ministrado nos aspectos relacionados ao ambiente, em sua maioria, é descontextualizado da realidade local sendo um discurso geralmente baseado em uma perspectiva naturalista, oferecendo pouco suporte formal para a existência da criticidade nos estudantes.

Corroborando com essas ideias iniciais, a hegemonização de uma postura conservadora para a Educação Ambiental (EA) no Brasil vem se estabelecendo na realidade escolar, reflexos da admissão da racionalidade dominante que acaba com a capacidade de, no ambiente escolar, gerar práticas críticas e criativas, além disso, por privilegiar visão fragmentadora e reducionista da questão ambiental, esvazia-se o sentido de um projeto de intervenção social pelas vias da educação (GUIMARÃES, 2003; SILVA et al., 2012).

Ratificando essa fala, Carvalho (2006, p.37) afirma que

a consequência de uma visão predominantemente naturalistaconservacionista é a redução do ambiente a apenas uma de suas dimensões, desprezando a riqueza da permanente interação entre a Natureza e a cultura humana. 
singularidades desta relação, portanto, acreditamos que isso se dará a partir da adoção de termos e de uma linguagem de proximidade entre Homem e Natureza, sendo este um fator preponderante para uma mudança positiva deste vínculo.

No contexto exposto surge o Antropoceno como narrativa para elucidar que futuro queremos construir, a partir de qual olhar para o ambiente. A inclusão do tema não envolve interesse no debate sobre essa ideia de época geológica, mas sim analisar essa proposta temporal a partir da reciprocidade de influências entre o ambiente e os homens, com o objetivo de diminuir a visão dualista na relação Homem-Natureza.

Este artigo tem o objetivo de efetuar uma reflexão sobre as relações entre a Sociedade e a Natureza a partir das correntes ambientais, destacando algumas das suas consequências para a Educação Ambiental no Brasil. Para tanto, tomamos por base a análise de autores selecionados, os quais julgamos de relevância para esse debate.

\section{Problemas ambientais e o desenraizamento do Homem}

A transição entre o mundo medieval e o mundo moderno deixou marcas longínquas, quando o humanismo passou a dar-lhe uma posição de autonomia e decisão, iniciando uma ruptura do que seria Sociedade e Natureza (SANTOS, 2006; GRÜN, 2012).

Esta substituição pode ser vista como positiva ou negativa a depender da interpretação do sujeito. As sociedades humanas criaram estruturas sociais e tecnológicas para sustentar inúmeros habitantes, aglomerados em grandes centros urbanos devido as logísticas desenvolvidas. No entanto, as grandes redes de deslocamento e distribuição criadas, geraram sérios danos ambientais, decorrentes de emissão de gases, grandes áreas desmatadas para implantação de áreas agricultáveis, além da perda de inúmeras espécies.

As estruturas sociais e tecnológicas criadas são mais perceptíveis em alguns segmentos da Sociedade do que em outros, como no modo em que a ciência é produzida, como cita Grün (2012, p.31) "no complexo que constitui a alquimia do moderno, a lógica de Francis Bacon é um componente importante na virada epistemológica que leva o mundo ao mecânico e à ética antropocêntrica".

A construção social é um campo misto de valores, crenças e saberes, nos quais o ambiente está inserido, e a depender do interesse das classes, dos diferentes arranjos e grupos sociais, este ambiente terá uma finalidade diferente podendo ser visto como recurso ou como detentor de direitos. Todavia, corroborando com Carvalho et al. (2009), se o que somos depende do nosso entorno, o desenraizamento do Homem com o mundo natural é reflexo de um entorno desconexo e fragmentado, sendo consequência a negação da Natureza. 
No que tange as questões ambientais, o que denominamos de crise nessa área, decorre de práticas e valores dominantes (SOLER; DIAS, 2016). São os padrões sociais do ocidente de base ética antropocêntrica e o modelo paradigmático da relação Sociedade-Natureza com uso irracional dos recursos naturais, que constituíram os problemas ambientais que hoje vemos (GRÜN, 2012).

A frequente degradação dos recursos naturais é uma crise de fortes influências culturais, sendo deste modo uma Sociedade dos consumidores e do desperdício, na qual as coisas são consumidas em um nível alucinante (LOUREIRO, 2012; SANTOS, et al., 2018).

Leff (2006) cita a necessidade de uma nova percepção, e esta nova percepção demandaria uma nova racionalidade, exigindo de todos uma ruptura para religação da cisão Homem-Natureza, sendo apropriado uma nova narrativa em que não se cuida "da Natureza" ou "dos Homens", mas que ambos se compreendam e complementem como unidade.

A crise civilizatória está antecipada de uma crise ética, cuja ausência de valores influenciam nas ações humanas em relação à Natureza, reclamando não somente uma solução técnica, mas também ética (LOUREIRO, 2012; JUNGES, 2001). Portanto, merecem atenção duas vertentes na discussão das questões ambientais: o antropocentrismo débil e o ecologismo biocentrista.

A primeira defende a responsabilidade do ser humano para com a Natureza, enquanto na segunda temos deveres diante da Natureza (JUNGES, 2001), como veremos detalhadamente mais adiante.

A negação do ambiente está embasada no humanismo antropocêntrico que rege a modernidade, a afirmação do Homem a partir da autonomia da razão com Bacon e Descartes, intensificando a dualidade sujeito e objeto na busca e defesa pela supremacia do Homem frente ao mundo natural. Nesse contexto sobre a questão ambiental, podemos afirmar que a Natureza e Sociedade são termos que se excluem.

Como reflexo das ações humanas do modelo econômico adotado e dos moldes como a ciência e a educação são feitas, temos: a desconexão, a fragmentação e a ausência de criticidade. A expansão descontrolada do saber, exemplifica-se como uma gigantesca torre de Babel com linguagens discordantes, em que "o conhecimento só é conhecimento enquanto organização, relacionado com as informações e inserido no contexto destas" (MORIN, 2003, p. 16.).

Morin (2003) destaca que os conhecimentos fragmentados só servem para usos técnicos, e não conseguem alimentar um pensamento capaz de considerar a situação humana neste grande desafio do nosso tempo.

A tradição intelectual limita o modo como cada indivíduo observa a Natureza; ela surge diante de cada um como uma imagem fragmentada da realidade (GONÇALVES et al., 2011). Portanto, temos uma Sociedade de 
padrões, fora dos contextos sem integração entre Homem e ambiente e sem a valoração necessária da Natureza.

O processo de fragmentação ao mesmo tempo que promove avanços no conhecimento, demanda a compreensão das especializações como parte de um todo complexo e inter-relacionado, a fim de não desvirtuarmos o próprio conhecimento adquirido (GALLO, 2002), o que é um grande desafio. Para superá-lo, é necessário o desenvolvimento de um trabalho que leve os indivíduos a refletirem sobre suas ações e atitudes, analisando o seu espaço enquanto lugar de vivência (OLIVEIRA, 2006).

Em distintos pontos do planeta, sociedades com diferentes trajetórias sociais, políticas e econômicas deparam-se com efeitos de alterações do clima global: desertificação, elevação do nível do mar, tempestades, enxurradas, redução da água doce e biodiversidade, assim como elevação da incidência de doenças infecciosas e parasitárias (ANDRADE, 2017).

Estes eventos afetam de modo mais severo as populações em situação de vulnerabilidade socioambiental, com péssimas condições de vida e que não dispõem em sua maioria de estruturas de segurança e apoio em meio a estes problemas decorrentes das alterações climáticas.

Os processos industriais, domésticos e produtivos afetaram o ambiente de tal modo, que é preciso mediar as ações para evitar maiores danos; ademais, as mudanças climáticas trazem graves consequências para continuação destes processos produtivos como são realizados hoje, colocando em foco a necessidade de arranjos mais sustentáveis.

Neste quesito o processo de Educação Ambiental nos espaços educativos sejam formais ou não, é bastante sugestivo, podendo, a depender do seu modo de execução, ser eficiente na formulação de uma nova racionalidade e percepção social, sobre os modos e a relação entre Sociedade e Natureza. Contudo, considerando o padrão societário ocidental, é preciso que a linguagem de aproximação destes temas seja apropriada, contextualizada aos locais nos quais esse processo formativo venha a ser desenvolvido.

\section{Os processos educativos e a Natureza: Educação Ambiental em foco}

A questão ambiental consiste na reciprocidade entre elementos sociais, políticos, econômicos, culturais e naturais (SAHEB; RODRIGUES, 2019). Portanto, espera-se que a educação se volte à construção de sujeitos que se compreendam como parte integrante do ambiente, considerando a interdependência entre ambos, refletindo-se numa forma de ser no mundo.

Gutiérrez (2013) cita que sistemas tradicionais de ensino são arraigados pela dimensão racionalista como sendo a forma mais importante do conhecimento. É preciso reorientar a educação a partir do princípio da sustentabilidade, retomar nossa educação em sua totalidade, implicando a revisão de currículos, programas e sistemas educacionais bem como do papel 
da escola, dos professores e da organização do trabalho escolar (GADOTTI, 2000).

É através dos processos educativos que surgem os elementos para que as pessoas se constituam como seres sociais e culturais (JULIANI; FREIRE, 2016). Além disso, tal processo é marcado pelo período histórico em que as pessoas se encontram, e dessa forma, possui uma intencionalidade (TOZONIREIS; CAMPOS, 2014). Devemos assim, promover ambientes educativos de mobilização e de intervenção sobre a realidade e seus problemas socioambientais, para superar as armadilhas paradigmáticas (Guimarães, 2004).

Entende-se por armadilhas paradigmáticas as limitações de compreensão e/ou a percepção parcializada da realidade, aprendendo a ver coisas tornando-se cego para outras, e mesmo não intencionalmente repetir as práticas do paradigma que resultou nos problemas ambientais que hoje existem.

Nesse aspecto, falar em transdisciplinaridade é pertinente não para desconsiderar as disciplinas ou eliminar o conhecimento produzido por estas, mas para situar estes conhecimentos em contextos históricos e sociais (RODRIGUES, 2014), porque os problemas emergentes só poderão ser solucionados pela correlação destes saberes.

Para que o processo educativo resulte em transformação social é necessário que os professores sejam críticos e reflexivos, com uma postura transdisciplinar, construtivista e comunicacional, capazes de compreender as relações entre Sociedade e ambiente (SANTOS; JACOBI, 2011). No entanto, pensando em termos de Brasil, na maioria dos casos os professores não possuem uma formação que lhes permita esse tipo de abordagem na escola (TOZONI-REIS; CAMPOS, 2014).

Assim, a formação inicial e continuada dos docentes deve considerar a necessidade de reconstrução progressiva dos conhecimentos relativos ao ambiente (SAHEB; RODRIGUES, 2019).

O processo educativo deve estar associado a uma reflexão sobre as questões ambientais, principalmente pela diversidade e diferentes identidades que existem na Sociedade (SATO, 2010). A autora aborda que além de induzir a repensar sobre a nossa responsabilidade ecológica, deve-se repensar os próprios modos de vida em Sociedade.

Nessa perspectiva, Guimarães (2004) aborda a dificuldade de compreender o mundo em sua totalidade complexa. Esta compreensão de mundo reflete para além da dominação Homem-Natureza, ampliando-se para as relações sociais, em vínculos de desigualdade, violência e individualismo.

Necessário uma Educação Ambiental crítica a partir da ressignificação do conhecimento existente, criando caminhos para aplicação e transformação da realidade ambiental nas escolas. Os caminhos para essa ressignificação do 
conhecimento, deve ocorrer através de uma leitura crítica do mundo, como cita Paulo Freire (1987), com o olhar da complexidade, segundo Edgar Morin (2003), em um espaço que é socioambiental, de acordo com Milton Santos (2006).

Para tanto, a Educação Ambiental para uma sociedade planetária se constitui num dos elementos essenciais que nos possibilitará substituir uma cultura de não pertencimento a Natureza, por outra de respeito, interdependência e solidariedade, sendo necessário processos pedagógicos dinâmicos, abertos e criativos que promovam interatividade e complexidade (GUTIÉRREZ, 2013; GIOMETTI; SILVA, 2016).

No caso do Brasil, o processo formativo para atingir os objetivos referentes as questões ambientais, veio através dos movimentos ambientalistas intensificados em meados da década de 1950, iniciando no país a luta pela inserção desse tema nos debates institucionais.

O avanço institucional dado a Educação Ambiental é significativo para a melhoria e implementação de ações neste âmbito dentro das escolas e comunidades no Brasil. $O$ ganho de qualidade na Educação Ambiental brasileira deve-se a organização desta dentro do país, a partir de sua trajetória de realizações pontuais até parcerias e projetos amplos (ANDRADE et al., 2014).

Contudo, o misto de conceituações, tendências ambientais, o histórico de ruptura das relações com o ambiente no ocidente e a fragilidade na realização das políticas públicas no Brasil, dão a Educação Ambiental tamanha superficialidade nas ações realizadas que, em muitos casos, suas ações tendenciam a ineficiência das intervenções.

Devido a tantas tendências que influenciam o olhar e as ações ambientais, Guimarães (2006, p. 11) alerta que "hoje não é mais possível afirmar que se faz Educação Ambiental sem qualificá-la. Já não é mais suficiente falar de uma Educação Ambiental genérica, conjugada no singular". Os educadores ambientais, com o tempo, perceberam que existem diferentes concepções de Educação Ambiental (LAYRARGUES, 2014).

Grande parte das abordagens é marcada pelo reducionismo, olhar biológico e ecológico da Educação Ambiental, desconecta as discussões econômicas, políticas, culturais e sociais, subjugando a ação humana no social e negando a existência do sujeito histórico (GONZAGA, 2016).

Não obstante, no que se refere a aplicação da Educação Ambiental no ensino formal devido a diversidade das concepções, cabe na maioria das vezes aos docentes o papel de reinventar-se ou articular-se, para conseguir atuar de maneira mais eficiente. Diferentes autores adotam distintos discursos e maneiras de praticar ações neste campo (SAUVÉ, 2005; SILVA et al., 2012).

$\mathrm{Na}$ Educação Ambiental é necessário que o docente trabalhe a integração Homem-Natureza, que seja possível a construção de novos 
conhecimentos, valores e atitudes (GUIMARÃES, 2005). Este deve ser um ponto de partida para a formação dos professores, suas concepções sobre ambiente e a forma como tratam do tema em sala de aula, quais abordagens e perspectivas ambientais possuem abrangência ou não nos conteúdos escolares.

Um dos maiores empecilhos para que a Educação Ambiental se efetive nas instituições de ensino é a dificuldade de os professores identificarem a relação entre o estilo de vida das pessoas e de suas ações e as questões ambientais (SAHEB; RODRIGUES, 2019).

É relevante compreender que sem uma Educação Ambiental crítica e contextualizada, todos estes encaminhamentos se esvaem. Uma postura ética não pode sê-la se não há uma contextualização das questões locais, das problemáticas socioambientais dos discentes e da comunidade. Partindo desse entendimento, a Educação Ambiental sempre será rasa e superficial se não houver uma conscientização da unicidade entre a escola e a Natureza em seu entorno, se não houver uma circunstância própria daqueles que, enquanto atores do processo formativo, sentem a problemática na pele.

É necessário que o Homem enquanto agente formador e formado por uma localidade, compreenda seu papel neste processo e posicione-se. Entretanto, como fazê-lo perceber seu papel enquanto cidadão formador e formado pelo seu entorno, se dentro das ações de Educação Ambiental no ensino formal são tantas as tendências ambientais abordadas, dando ao Homem e ao ambiente papéis destoantes e contrários? Como fazê-lo enxergar o Homem e a Natureza sem uma dicotomia?

\section{Tendências ambientais tradicionais: antropocentrismo, biocentrismo e suas influências na Educação Ambiental}

As maneiras como os homens veem a Natureza e agem sobre ela são moldadas pelos paradigmas ambientais compartilhados, comumente classificados na literatura, como antropocêntricos e biocêntricos (SILVA; REIS; AMÂNCIO, 2011).

A percepção do mundo, da vida social e dos meios de produção esteve (e está) centrada nos seres humanos, ou seja, visão de mundo antropocêntrica (MARTINI; RIBEIRO, 2011).

O modo como a Natureza é vista representa a exploração e apropriação pela cultura e pelo humano (JUNQUEIRA; KINDEL, 2009). De acordo com Boff (2005, p.31) "o antropocentrismo configura aquela atitude mediante a qual somente se vê sentido nas coisas à medida que elas se ordenam ao ser humano e satisfazem seus desejos...".

O antropocentrismo caracteriza-se por uma visão instrumental da Natureza, através da ação humana de controle e domínio com o objetivo de exploração dos seus recursos (ALMEIDA, 2005). Essa abordagem se identifica 
com as formas do pensamento científico característicos da civilização ocidental, apresentando-se pelo estabelecimento de uma hierarquia das diferentes formas de vida, podendo refletir o desejo de controle das forças da Natureza (ALMEIDA, 2005).

Para Armstrong e Botzler (2004, p. 271), o antropocentrismo seria "a perspectiva filosófica em que princípios éticos são aplicáveis exclusivamente aos humanos, e as necessidades e interesses humanos possuem os mais elevados valor e importância".

Com a ampliação geometricamente crescente dos efeitos das ações humanas sobre a Natureza, por meio do desenvolvimento científico e tecnológico, o antropocentrismo passou a ser apontado por muitos como causa das crises ambiental e social que vivemos (CHOUERI JUNIOR, 2010).

A interação entre o Homem e a Natureza ao longo do período moderno de desenvolvimento, explica como se efetivou a modernização da técnica e exploração da Natureza, sendo possível reconhecer a forma como o ser humano entende sua posição em relação ao ambiente natural, justificando através disso suas práticas (ROVANI, 2011).

Sobre a educação e o antropocentrismo, Stroppa e Viotto (2014, p.123) afirmam que é "sob o crivo da cultura antropocêntrica que nossa educação foi fundamentada, fazendo com que acreditássemos que podemos determinar sobre a vida de outras espécies".

Refletindo sobre as raízes da centralidade humana e sua exclusividade moral, Almeida (2005) afirma que deriva de Aristóteles (384-322 a.C.), e particularmente em Francis Bacon (1561-1626) e Descartes (1596-1650), que a ideia do ser humano como dominador do mundo encontra suas raízes mais fortes. Pensamento influenciador até hoje, onde a Natureza é para uso e deleite do Homem. Além disso, as próprias justificativas de proteção ambiental que se tornaram bandeira em larga escala, são de perspectiva antropocêntrica ao considerarmos que precisamos conservar o planeta para as próximas gerações (FERREIRA; BOMFIN, 2010).

Os avanços e descobertas da ciência moderna, baseada no paradigma cartesiano, atingiram melhorias para as Sociedades de modo incontestável. Por outro lado, são inquestionáveis também, as consequências do cartesianismo nos dias de hoje principalmente no que se refere ao dualismo, oposição Homem-Natureza e sujeito-objeto (MOLINARO; D'ÁVILA; NIENCHESKI, 2012), sendo evidentemente duvidoso que esse fenômeno continue por muito tempo (VEIGA, 2017).

A orientação antropocêntrica que embasou atitudes humanas durante séculos, teve seus reflexos e consequências marcantes agora quando o crescimento industrial desmedido provocou danos irreparáveis ao ambiente (MOLINARO, et al., 2012). 
São inúmeros os responsáveis pelo enraizamento do antropocentrismo, logo, o cartesianismo, o dualismo e a superioridade dos interesses humanos permearam todos os âmbitos, tornando ínfimas as questões ambientais, quando inexiste algum tipo de interesse humano.

Contrapondo a tendência antropocêntrica, surge a tendência biocêntrica, “...visando dar importância a todos os seres viventes..."(STROPPA; VIOTTO, 2014, p. 124). Teoria elaborada por Paul W. Taylor (1987), o biocentrismo perpassa o valor moral para além dos seres humanos, ampliando-o para todos os seres viventes.

A valoração moral para todos os seres vivos diz respeito às transformações e adaptações das espécies, como forma de manutenção da existência e não prescinde de qualquer finalidade humana (SILVA; RECH, 2017).

Através do olhar biocêntrico não apenas os seres humanos são titulares de direito, inclui-se os animais na importância jurídica, que merece consideração pelo que é, pelo caráter ímpar de sua existência e pelo fato de estar no mundo (LEVAl, 2011).

Para o biocentrismo a ética ambiental não é um problema apenas da psicologia, mas de biologia. No biocentrismo, o ser humano estabelece uma relação harmônica com o ambiente (MANTILLA, 2018).

Essa perspectiva defende a existência de valor nos demais seres vivos, ou seja, por conta disso, do ponto de vista ético o biocentrismo deve prevalecer. Inclusive, já podemos nos deparar com o surgimento de estudos que apoiam a visão jurídica de tutela de todos os seres vivos como sujeitos de direito (OLIVEIRA, 2014).

Portanto, domina a perspectiva de que "...a vida é considerada um fenômeno único, tendo a Natureza valor intrínseco, e não instrumental, o que gerará uma consideração aos seres vivos não integrantes da raça humana..."(AMADO, 2014, p.31). Dessa forma, todo ser vivente tem valor intrínseco e inerente em si, e não apenas valor utilitário em prol dos seres humanos.

Nesta concepção, cabe aos homens o dever de escolher as ações que menor impactem às demais espécies, evitando conflito de interesse entre as espécies (SILVA; RECH, 2017).

Entretanto, a inviabilidade do biocentrismo por apresentar-se como limitado e individual, com visão romântica das relações entre os seres na Natureza, a partir da não interferência humana, já designa utopia (SILVA; $\mathrm{RECH}, 2017)$.

Considerando estas duas tendências ambientais, fica claro o quão heterogêneo é o discurso ambiental, onde temos diversas combinações de posicionamentos que acarretam diferentes abordagens nas ações de Educação Ambiental. 
E neste misto estão os docentes, formados nos mais diversos cursos: Biologia, Geografia, Português, Matemática, História, Filosofia, Sociologia; e cada um deles, também com suas tendências particulares, gerando um caldeirão de informações e atuações, embaralhando ainda mais a temática nas escolas.

São diversas as abordagens relacionadas a questão ambiental na educação (RAMOS, 2006). Entretanto, apesar da diversidade, muitos autores destacam 0 predomínio da abordagem naturalista dos problemas socioambientais, refletindo diretamente no campo educacional (SANTOS; NOBRE, 2018).

Por abordagem naturalista entende-se, ênfase ao biológico e ecológico às questões relacionadas ao ambiente, privilegiando danos físico-químicos no ambiente em detrimento dos aspectos relacionados ao político-econômico e social (FLICKINGER, 1994; LEFF, 2001.).

Interessante é reconhecer que este posicionamento naturalista no viés da Educação Ambiental, não favorece a aproximação da relação HomemNatureza. Pelo contrário, torna-a ainda mais dicotômica porque em contraponto a esta visão naturalista, está exatamente um modelo racionalista e antropocêntrico de mundo. O Homem dificilmente se coloca como um elemento da Natureza, mas à parte, um observador e/ou explorador, e esse distanciamento em relação a Natureza fundamenta ações humanas tidas como racionais (REIGOTA, 2014). Logo, entendemos que a abordagem da visão naturalista nas concepções de Educação Ambiental amplia a cisão entre Homem-ambiente.

Em contrapartida, a Pedagogia Antropocêntrica está presente em todos os espaços educativos da sociedade moderna; é a ação pedagógica que ensina visão de mundo do antropocentrismo (FELIPE, 2009; SINGER, 2010; CAROLA, 2014). Carola e Constante (2015) esclarecem que adicionaram o termo "pedagogia" para enfatizar o aspecto educativo do antropocentrismo na escola.

As sociedades ocidentais são marcadas por uma visão de mundo antropocêntrica, onde seu modelo educacional espelha este paradigma e, para ocorrer mudança, no aspecto pedagógico, seria necessário conduzir os jovens a compreensão menos antropocêntrica da realidade a partir da revisão do conteúdo programático das disciplinas, além da introdução de métodos de aprendizagem diferenciado (OLIVEIRA; DIAS, 2018).

No Brasil, de modo subtendido ou manifesto claramente, a escola moderna transmite a pedagogia da cultura antropocêntrica, seja por livros didáticos ou práticas de ensino, sendo os livros formulados na concepção do Homem antropocêntrico (COROLA; CONSTANTE, 2015). O mito do antropocentrismo é como elemento "quase natural" nos livros onde "não raro, propostas de Educação Ambiental são apanhadas na fina e sofisticada malha discursiva do cartesiano" (GRÜN, 2012, p.47). 
Com base no exposto, carecemos de uma pedagogia que promova a conscientização do sentido crítico, que ensine uma condição ontológica de cuidar do mundo junto as demais formas de vida, refletido no discurso escrito e reproduzido na fala dos docentes (COROLA, 2014).

Gruenewald (2015) afirma que a Educação Ambiental é disciplinada por uma ciência convencional, o que negligencia os aspectos sociais, econômicos e culturais, legitimando as tendências convencionais que geraram os problemas ecológicos. Portanto, na educação escolar a Educação Ambiental requer discussões e reflexões críticas, porque no modo como está sendo feito, põe os agentes causadores dos problemas ambientais de modo simplificador e reducionista (MAIA; TEIXEIRA, 2015).

$O$ modo antropocêntrico de ensinar a Natureza é reflexo das bases filosóficas do século XVII, e desde então, a Natureza é assimilada como estando a serviço do Homem, influenciou e edificou profundamente a educação moderna, ensinando como se o homem não fizesse parte dela, ensinando aos educandos sobre a "utilidade" dos animais e outros seres vivos (KINDEL, 2012; GRÜN, 2012). Nesse contexto, a Natureza é vista como recurso natural, visão também presente nos livros-texto em que se apresenta a natureza e seus elementos como uteis ou nocivos, com ou sem valor de troca e uso (JUNQUEIRA; KINDEL, 2009).

Temos a necessidade de fazer a inversão lógica, procurando trabalhar a importância de cada elemento na Natureza, fazendo com que o educando pense no mundo de modo menos antropocêntrico (KINDEL, 2012).

Entretanto, não é preciso olhar para visão antropocêntrica como algo ruim, e sim como visão que precisa ser problematizada produzindo ensino mais voltado a visão sistêmica (LISBOA, 2012). Não significa abandonar o conhecimento prévio e considerar somente teorias novas, mas reconhecer limitações do paradigma clássico (RODRIGUEZ; SILVA, 2016).

Portanto, é preciso uma narrativa que promova mudança na abordagem "Homem-Natureza" e, nessa perspectiva, surgem muitas ideias ligadas ao denominado Antropoceno.

\section{Antropoceno: uma narrativa promotora de mudança?}

O Antropoceno, conceito sugerido por Paul Crutzen (2002) no artigo "Geology of mankind", publicado na Revista Nature, seria o novo tempo geológico, época em que a humanidade é elemento dominante nos processos que comandam a dinâmica terrestre.

Há crescente consenso de que seres humanos transformaram o padrão e processos dos ecossistemas na maior parte da biosfera (ELLIS, et al., 2010). Ellis (2015) cita que não há como sustentar a população em ecossistemas não transformados, portanto, é preciso que a humanidade abrace o papel de modelador e administrador da ecologia da terra; conservando espaços de 
Natureza selvagem, "projetando espaços em que podemos deixar a Natureza em paz” (ELLIS, 2015, p. 28).

Os seres humanos projetaram ecossistemas para sustentar as populações de sua espécie, a partir da incomparável capacidade de transmitir conhecimentos e informações ao longo do tempo, resultando na expansão do nicho humano através dos recursos transmitidos culturalmente.

Enquanto proposta, o Antropoceno traz abordagem que temos nas ações humanas as principais mudanças físicas e ambientais atuais, portanto, é um paradigma que liga Ciências Naturais, Ciências Sociais e Humanidades (ELLIS, 2017).

Dessa forma, inúmeras mudanças que as sociedades humanas fizeram ao longo das gerações na Terra, permitiram a sustentação da sua espécie, mas também levou a extinção de outras inúmeras. Porém, agir e cooperar para essa evolução das sociedades intencionalmente traz consigo consequências humanas, como cita Ellis (2015), compreendidas como a junção das consequências pretendidas versus as consequências não-intencionais das ações, somadas com responsabilidade social por essas consequências (ELLIS, 2015).

Reconhecer consequências não-intencionais das ações e agindo de modo a mitigar estas consequências, traz a possibilidade de emergir em nova compreensão de mundo, na qual a tomada de decisão para determinada consequência pretendida, resulte em mitigação das consequências nãointencionais, e os procedimentos técnicos, tecnológicos e construções transdisciplinares mostram que é possível.

Trazemos, portanto, a importância do Antropoceno para debate como narrativa para elucidar que futuro queremos construir, a partir de que olhar para o ambiente, inclusive nas nossas formações docentes e práticas educacionais, como alternativa às visões antropocêntrica e biocêntrica, até porque:

Um antropocentrismo desordenado não deve necessariamente ser substituído por um "biocentrismo", porque isto implicaria introduzir um novo desequilíbrio que não só não resolverá os problemas existentes, mas acrescentará outros. Não se pode exigir do ser humano um compromisso para com o mundo, se ao mesmo tempo não se reconhecem e valorizam as suas peculiares capacidades de conhecimento, vontade, liberdade e responsabilidade (FRANCISCO, 2011, p. 118).

É necessária uma mudança de narrativa, inserida no processo de ensino-aprendizagem na sala de aula, que promova valorização do avanço das Sociedades humanas, da compreensão de que a Natureza não é mais a mesma, ainda assim, podemos modificá-la nos moldes mais sustentáveis possíveis, de forma positiva e consciente. 
O Antropoceno conceitua-se como oportunidade educacional, desde que evite paradigmas que causaram a crise ecológica atual, os autores trabalham na perspectiva de que humanos e não humanos moldam nosso mundo comum (TAYLOR, 2013; TAYLOR; PACINI-KETCHABAW, 2015). Nesse aspecto de oportunidade educacional:

As fronteiras entre a ciência e o processo educacional provavelmente desaparecerão, dando caminho para novas abordagens transdisciplinares, com a ciência e a Sociedade interagindo de novas formas. Em outras palavras, a educação para o Antropoceno passa por uma grande variedade de desafios, bem como de oportunidades (LEINFELDER, 2013, p.10).

Contudo, se o Antropoceno é oportunidade educacional (tanto na pesquisa como na prática), para reformular e questionar as relações e fronteiras entre Sociedade-Natureza, é preciso repensar a linguagem usada em documentos educacionais, evitando reprodução do modelo pedagógico de cunho mercantilista, que põe a Natureza unicamente como recurso (LLOROBIDART, 2015).

Nesse contexto, construir uma ciência e educação ecológica a partir do Antropoceno ajudará a Sociedade a tomar posse de uma biosfera que já alteramos irreversivelmente, trazendo melhor compreensão de como gerenciar os elementos que criamos/mantemos onde vivemos (ELLIS; RAMANKUTTY, 2008).

Através de uma educação voltada ao ambiente, adotando escalas de interferência humana como forma de análise, podemos compreender o papel de cada um nas mudanças que ocorrem no planeta, entendendo o Antropoceno como resultado de ações coletivas e individuais ao longo dos anos (OLIVEIRA et al., 2016). Deste modo, a apropriação desse entendimento contribui com alternativas para minimizar efeitos das ações humanas, pensando em soluções sustentáveis (não apenas tecnológicas, mas comportamentais e políticas) que possam ser adotadas (MATOS et al., 2017).

O Antropoceno exige, portanto, transdisciplinaridade, novas abordagens entre Ciência e Sociedade, pois permeia fronteiras disciplinares e desafios estabelecidos na academia e nas práticas pedagógicas (TRISCHLER, 2013; LEINFELDER, 2013).

Neste debate sobre Antropoceno, permite questionar a intencionalidade humana, a visão racionalista moderna e decisões analíticas que partem desse pressuposto (FERRÃO, 2017).

Conforme Leinfelder (2013), o elemento crucial para uma mudança em larga escala seria uma transformação social em que ciência, tecnologia e pesquisa trabalhem em conjunto com o público em geral, incorporando uma educação transformadora, transdisciplinar e que facilite o discurso, reflexão e 
participação para direcionar a um Antropoceno que permita uso justo e desenvolvimento para futuras gerações. A partir disso, iniciaremos o começo de novas formas de educação.

A perspectiva de inclusão do conceito e das propostas do Antropoceno, busca equilíbrio entre o que denominamos tradicionalmente de Natureza e Sociedade, com o olhar voltado a diminuir essa visão dualista. Latour (2014) afirma que o conceito de Antropoceno, se usado de maneira sensata, atentanos para o fim da bifurcação entre Natureza e Humanidade.

Caminhar em direção a um Antropoceno sustentável eticamente implica em consequências individuais, sociais, estilos de vida e atitudes, onde não é cabível continuar com a visão dualista de uma "boa" Natureza e "má" humanidade, diante do grau de interferência antropogênica nos sistemas terrestres. Nesse caso, os seres humanos devem considerar-se parte integrante dessa "nova" Natureza de hoje, implementando isso através de educação que permita uma Sociedade sustentável e duradoura (LEINFELDER, 2013).

Nota-se então que, na educação e no ensino, o Antropoceno tornou-se instrumento poderoso para testar novas abordagens de Educação Ambiental, através da interdisciplinaridade e transdisciplinaridade, transcendendo barreiras (LEINFELDER, 2013; MÖLLERS, 2014; LLORO-BIDART, 2015; TRISCHLER, 2016).

\section{Considerações Finais}

O advento do Novo Coronavírus em escala mundial tem apresentado uma série de consequências. Entre outras discussões, muitos falam que o mundo pós pandemia terá que se reinventar, chegando agora de forma mais expandida alguns dados e ideias que já vinham sendo expostas em âmbito mais restrito à comunidade científica e certos setores governamentais, a ponto de também se pensar em fase de revalorização da Ciência em escala planetária. De fato, esperamos e torcemos que essa trágica experiência para a saúde pública que afetou todas as demais áreas seja um marco para o estabelecimento de novos caminhos para humanidade, baseados no que muitos denominam sustentabilidade.

Em relação a Educação Ambiental, cremos que esse momento também poderá ser benéfico, tornando essa área do conhecimento com maior capacidade para traduzir uma realidade complexa em práticas pedagógicas que colaborem para formação de cidadãos que melhor compreendam a realidade, despertando assim senso crítico para prática de ações necessárias.

Entretanto, entre o que somos e o que viremos a ser, o que construímos e o que passaremos a construir, passa por uma transformação na forma de pensar que somente o tempo irá dizer onde de fato chegaremos nessa ideia de nova racionalidade. 
Agradecimentos: $O$ presente trabalho foi realizado com apoio da Coordenação de Aperfeiçoamento de Pessoal de Nível Superior - Brasil (CAPES) - Código de Financiamento 001, fornecendo bolsa de estudos para a primeira autora desta publicação.

\section{Referências}

ALMEIDA, A.J.C. Concepções ambientalista dos professores: suas implicações em Educação Ambiental. Tese, Universidade Aberta, Lisboa. 2005.

AMADO, F.A.T. Direito Ambiental Esquematizado. R. Janeiro: Forense. 2014. ANDRADE, D. F.; LUCA, A. Q.; CASTELLANO, M.; RISSATO, C. G.; SORRENTINO, M. Da pedagogia à política e da política à pedagogia: uma abordagem sobre a construção de políticas públicas em Educação Ambiental no Brasil. Ciência \& Educação (Bauru), v. 20, p. 817-832, 2014.

ANDRADE, H. V. Mapeamento das políticas estaduais de adaptação das cidades às mudanças climáticas no Brasil. Revista Geografia Acadêmica, v.11, p. 24-49, 2017.

ARMSTRONG, S.; BOTZLER, R. Anthropocentrism. In: ARMSTRONG S. (org.). Environmental Ethics: divergence and convergence. New York: McGraw-Hill, p. 270-273, 2004.

BOFF, L. O cuidado essencial: princípio de um novo ethos. Inclusão Social, v. 1, 2005. Recuperado de http://revista.ibict.br/inclusao/article/view/1503

CAROLA, C.R. Pedagogia antropocêntrica versus ecopedagogia: a ruptura necessária para uma educação libertadora. Revista Unifreire, v.1, p.69-77, 2014.

CAROLA, C.R.; CONSTANTE, C.E.A. Antropocentrismo pedagógico e naturalização da exploração ambiental no ensino de ciências (Brasil, 19601970). Revista Eletrônica do Mestrado em Educação Ambiental, v.32, p.358-379, 2015.

CARVALHO, I. C. M. Educação Ambiental: a formação do sujeito ecológico. São Paulo: Cortez. 2006.

CARVALHO, I. C. M.; GRÜN, M.; AVANZI, M. R. Paisagens da compreensão: contribuições da hermenêutica e da fenomenologia para uma epistemologia da Educação Ambiental. Cadernos CEDES, v. 29, p. 99-115, 2009.

CHOUERI JUNIOR, N. Investigação em torno do antropocentrismo e da atual crise ecológica. Dissertação, Univ. Federal do Rio Grande do Norte, 2010.

CRUTZEN, P. J. Geology of mankind. Revista Nature, v. 415, p. 23, 2002.

Ellis, Erle Christopher; Ramankutty, Navin. Putting people in the map: anthropogenic biomes of the world. Frontiers in Ecology and the Environment, v.6, n.8, pp. 439-447, 2008.

ELLIS, E. C.; GOLDEWIJK, K. K.; SIEBERT, S.; LIGHTMAN, D.; RAMANKUTTY, N. Anthropogenic transformation of the biomes, 1700 to 2000. Global Ecology and Biogeography, v. 19, p. 589-606, 2010. 
ELLIS, E. C. Too big for nature. In: PYNE, S. J. (org.). After Preservation: Saving American Nature in the Age of Humans. University of Chicago Press, Chicago. 2015

ELLIS, E. C. Anthropogenic transformation of the terrestrial biosphere. Proceedings of the Royal Society A: Mathematical, Physical and Engineering Science v. 369, p. 1010-1035, 2011.

FELIPE, S. T. Antropocentrismo, sencientismo e biocentrismo: perspectiva éticas abolicionistas, bem-estaristas e conservadoras e o estatuto de animais não-humanos. Revista Páginas de Filosofia, v.1, p. 1-29, 2009.

FERREIRA, F.; BOMFIN, Z. A. C. Sustentabilidade Ambiental: visão antropocêntrica ou biocêntrica? Ambientalmente sustentable, v. 9, p. 37-51, 2010.

FERRÃO, J.O Antropoceno como narrativa: uma lente útil para entender o presente e imaginar o futuro? Revista da Faculdade de Letras da Universidade de Coimbra, v. 3, p. 205-221, 2017.

FLICKINGER, H. O ambiente epistemológico da Educação Ambiental. Educação e realidade, v.19, p. 197-207, 1994.

FRANCISCO, P.. Carta encíclica Laudato Si' do Santo Padre Francisco sobre o cuidado da casa comum. Disponível em: <https://www.puccampinas.edu.br/wp-content/uploads/2016/03/NFC-Carta-Enciclica-laudato-

si.pdf>. 2011.

FREIRE, P. Pedagogia do Oprimido. Rio de Janeiro: Paz e Terra. 1987.

GADOTTI, M. Pedagogia da Terra. São Paulo: Peirópolis. 2000.

GALLO, S. Transversalidade e educação: pensando uma educação nãodisciplinar. In: GARCIA, R. L.; ALVES, N. (org.). O sentido da escola. Rio de Janeiro: DP\&A. 2002

GIOMETTI, A. B. R.; SILVA, T. P. A Educação Ambiental frente a questão socioambiental. In: ALMAZÁN, J. S.; GUTIÉRREZ, N. S. N. (org.). Educación y sustentabilidad: México-Brasil. Ediciones y Gráficos Eón, p. 93-107, 2016.

GONÇALVES, A. M.; CABO, P. A.; FERNANDES, A. J.; RIBEIRO, M. I. Repensar os curriculos para uma efetiva cidadania ambiental. Egitania Sciencia, Guarda, v. 9, p. 75-100, 2011.

GONZAGA, M. J. B. O naturalismo presente na visão de professores sobre meio ambiente e as marcas da Educação Ambiental conservadora. Revista Brasileira De Educação Ambiental, v. 11, p. 54-65, 2016.

GRUENEWALD, D. A. A Foucauldian Analysis of Environmental Education: Toward the Socioecological Challenge of the Earth Charter. Curriculum Inquiry, v. 34, p. 71-107, 2004.

GRÜN, M. Ética e Educação Ambiental: A conexão necessária. CampinasSão Paulo: Papirus. 2012

GUIMARÃES, M. Educadores ambientais em uma perspectiva crítica: reflexões em Xerém. Tese, Universidade Federal Rural do Rio de Janeiro. 2003 
GUIMARÃES, M. Educação Ambiental Crítica. In: LAYRARGUES, P.P. (org.). Identidades da Educação Ambiental Brasileira. Brasília: Ministério do Meio Ambiente, p. 25-34, 2004.

GUIMARÃES, M. A dimensão ambiental na educação. Campinas: Papirus. 2005

GUIMARÃES, M. Armadilha paradigmática na Educação Ambiental. In: LOUREIRO, C. F. B. (org.). Pensamento complexo, dialética e Educação Ambiental. São Paulo: Cortez, p. 15-29, 2006.

JULIANI, S. F.; FREIRE, L. M. Representações discursivas de Educação Ambiental: uma análise no âmbito da extensão universitária. Alexandria: Revista de Educação em Ciência e Tecnologia, v. 9, p. 35-60, 2016.

JUNGES, J. R. Ética ecológica: antropocentrismo ou biocentrismo? Revista Perspectiva Teológica, v. 33, p. 33-66, 2001.

JUNQUEIRA, H.; KINDEL, E. A. I. Leitura e escrita no ensino de ciências e biologia: a visão antropocêntrica. Cadernos do Aplicação (UFRGS), v. 22, p. 145-161, 2009.

KINDEL, E. A. I. Práticas pedagógicas em Ciências: espaço, tempo e corporeidade. Erechim: Edelbra. 2012

LAYRARGUES, P. P.; LIMA, G. F. C. As macrotendências político-pedagógicas da Educação Ambiental brasileira. Ambiente \& Sociedade, São Paulo, v. 17, p. 23-40, 2014. Disponível

LATOUR, B. 2014. Para distinguir amigos e inimigos no tempo do Antropoceno. Revista de Antropologia, v. 57, p. 11-31, 2014.

LEINFELDER, R. Assuming Responsibilities for the Anthropocene: Challenges and Opportunities in Education. In: TRISCHLER, H. (org.). Anthropocene: Envisioning the Future of the Age of Humans. Munich, Germany: Rachel Carson Center, p. 9-28, 2013.

LEVAI, L. F. Ética ambiental biocêntrica: pensamento compassivo e respeito à vida. Revista Eletrônica de Ciências Jurídicas e Sociais da Universidade Cruzeiro do Sul, v. 1, p. 7-20, 2011.

LEFF, E. Epistemologia Ambiental. São Paulo: Cortez. 2001

LEFF, E. 2006. Racionalidade ambiental: a reapropriação social da Natureza. Rio de Janeiro: Civilização Brasileira. 2006.

LISBOA, C. P. Itinerário de formação: reflexões acerca de um curso sobre Educação Ambiental. In: LISBOA, C. P.; KINDEL, E. A. I. (org.). Educação Ambiental: da teoria à prática. Porto Alegre: Mediação, p.99-119, 2012.

LLORO-BIDART, T. 2015. A Political Ecology of Education in/for the Anthropocene. Environment and Society: Advances in Research, v. 6, p. 128-148, 2015.

LOUREIRO, C. F. B. Trajetória e fundamentos da Educação Ambiental. São Paulo: Cortez. 2012 
MAIA, J. S. S. ; TEIXEIRA, L. A. Formação de professores e Educação Ambiental na escola pública: contribuições da pedagogia histórico-crítica. Revista HISTEDBR On-Line, v. 15, p. 293-305, 2015.

MARTINI, B.; RIBEIRO, C. G. Antropoceno: a época da humanidade? Ciência Hoje, v. 48, p. 38-43, 2011.

MANTILLA, E. E. Del antropocentrismo al biocentrismo: un recorrido hacia la educación para el desarrollo sostenible. Revista Agrollanía, v.16, p.20-25, 2018.

MOLINARO, C. A.; D'ÁVILA, C. D. B.; NIENCHESKI, L. Z. Gaia entre mordaças dilemáticas: antropocentrismo vs ecocentrismo. Prima Facie, João Pessoa, v. 11, p. 3-20, 2012.

MÖLLERS, N. Das Anthropozän: Wie ein neuer Blick auf Mensch und Natur das Museum verändert. In: DÜSELDER, H. (org.). Umweltgeschichte: Forschung und Vermittlung in Universita"t, Museum und Schule. Cologne: Böhlau, p. 217-229, 2014.

MORIN, E. Articular os saberes. In: GARCIA, R. L.; ALVES, N. (org.). 0 sentido da escola. Rio de Janeiro: DP\&A, p. 65-80, 2002.

MORIN, E. Terra-Pátria. Porto Alegre: Sulina. 2003.

MORIN, E. A cabeça-feita: repensar a reforma, reformar o pensamento. Rio de Janeiro: Bertrand Brasil. 2003.

OLIVEIRA, N. A. S. Educação Ambiental e a percepção fenomenológica, através de mapas mentais. Revista eletrônica do Mestrado em Educação Ambiental, v. 16, 2006.

OLIVEIRA, C. C.; SILVA, G. I.; MARTINS, I.; LAMIM-GUEDES, V. Antropoceno e a escala da interferência humana de Pierre Dansereau: atividades de Educação Ambiental. Revista Educação Ambiental em Ação, v. 58, 2016.

OLIVEIRA, F. A. G.; DIAS, M. C. Educação, Ética Animal e Ambiental: Destituindo O Paradigma Antropocêntrico. Revista Espaço Do Currículo, v. 3, p. 370-378, 2018.

RODRIGUES, A. R. S. Educação Ambiental em tempos de transição paradigmática: entrelaçando saberes "disciplinados". Ciência \& Educação (Bauru), v. 20, p. 195-206, 2014

RODRIGUEZ, J. M. M.; SILVA, E. V. Educação Ambiental e Desenvolvimento Sustentável: problemática, tendências e desafios. Fortaleza: Expressão Gráfica e Editora. 2016.

ROVANI, A. Ética ambiental: a problemática concepção do Homem em relação à Natureza. Revista Direitos Culturais, v. 6, p. 13-22, 2011.

SAHEB, D.; RODRIGUES, D. G. Infância e experiências em Educação Ambiental: um estudo da prática docente na educação infantil. Revista Lusófona de Educação, Lisbon, v. 43, p. 59-74, 2019.

SANTOS, M. A Natureza do Espaço: Técnica e Tempo, Razão e Emoção. São Paulo: Editora da Universidade de São Paulo. 2006 
SANTOS, V. M. N.; JACOBI, P. R. Formação de professores e cidadania: projetos escolares no estudo do ambiente. Educação e Pesquisa, v. 37, p. 263-278, 2011.

SANTOS, T. M. M.; OLIVEIRA, J. L. S..; OLIVEIRA, H. M.; SILVA, E. Recursos hídricos: problemas ambientais e a importância da Educação e Percepção Ambiental. Revista Educação Ambiental em Ação, v. 65, 2018.

SANTOS, A. L. M.; NOBRE, S. B. Concepções de Educação Ambiental: quais os objetivos de Professores que procuram o Centro de Educação Ambiental de Sapiranga/RS (CEMEAM)? Revista Educação Ambiental Em Ação, v. 65, p. 1-6, 2018.

SAUVÉ, L. Uma cartografia das correntes em Educação Ambiental. In: CARVALHO, I. C.M.; SATO, M. Educação Ambiental: pesquisa e desafios. Porto Alegre: Artmed, p. 17-44, 2005.

SILVA, L. O.; COSTA, A. P. L.; ALMEIDA, E. A. Educação Ambiental: o despertar de uma proposta crítica para a formação do sujeito ecológico. Revista Holos, v. 1, p. 110-123, 2012.

SINGER, P. Libertação animal. São Paulo, Martins Fontes. 2010.

SOLER, A.; DIAS, E. A. A Educação Ambiental na crise ecológica contemporânea. Revista Acesso Livre, v. 9, p. 146-164, 2016.

STROPPA, T.; VIOTTO, T. B. 2014. Antropocentrismo x Biocentrismo: um embate importante. Revista Brasileira de Direito Animal, v.13, p.119-133, 2014.

TAYLOR, P. W. Respect for Nature: a theory of environmental ethics. New Jersey, Princeton: Princeton University Press. 1987.

TAYLOR, A. Educating for Sustainable Common Worlds at the Eve of the Anthropocene. University of Western Sydney Spring School for Sustainability. 2013.

TAYLOR, A.; PACINI-KETCHABAW, V. Learning with children, ants, and worms in the Anthropocene: towards a common world pedagogy of multispecies vulnerability. Pedagogy, Culture \& Society, v. 23, p. 507-529, 2015.

TOZONI-REIS, M. F. C.; CAMPOS, L. M. L. Educação Ambiental escolar, formação humana e formação de professores: articulações necessárias. Educar em Revista, v. 3, p. 145-162, 2014.

TRISCHLER, H. Introduction. In: TRISCHLER, H. (org.). Anthropocene: Envisioning the Future of the Age of Humans. Munich, Germany: Rachel Carson Center, p. 5-8, 2013.

TRISCHLER, H. The Anthropocene. NTM, v. 24, p. 309-335, 2016.

VEIGA, J. E. A primeira utopia do Antropoceno. Ambiente e Sociedade, v. 20, p. 227-246, 2017. 